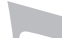
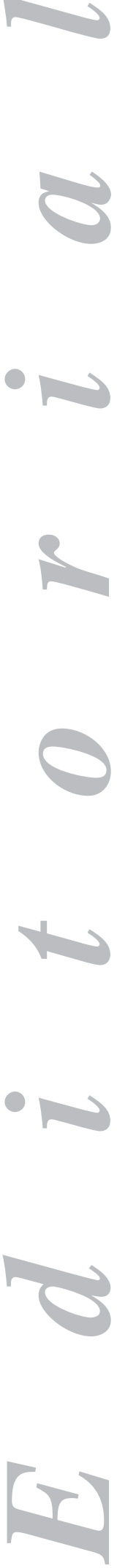

\title{
Coeliac disease in the oral mucosa?
}

Coeliac disease (CD) is a small intestinal hypersensitivity occurring in some individuals to gluten prolamins from wheat, rye, barley $(1,2)$ and some oat species $(3,4)$. CD has a strong genetic background $(10 \%$ prevalence in first degree relatives coupled with $30 \%$ concordance in dizygotic and $70 \%$ in monozygotic twins) $(1,2)$ as virtually all the patients are HLA-DQ2+ and/or HLA-DQ8+. CD patients are also positive for some serological markers (IgA anti-endomysial and/or IgA anti-tissue transglutaminase -tTG-) and have gluten-induced duodenal morphological changes characterized by: a) Lymphocyte infiltrates at the intraepithelial compartment; b) crypt hyperplasia; and c) villous atrophy $(1,2,5)$. Despite CD is the most common food intolerance in Western European countries, with an estimated prevalence in Europe that may rise up to $1 \%$ in the general population $(6,7)$, only 1 out of 7 or 10 affected individuals are correctly diagnosed (8). Non-CD gluten intolerance has also been recently recognized $(9,10)$ adding an extra difficulty to CD diagnosis. At present, the only treatment for $\mathrm{CD}$ and non-CD gluten intolerance is a life-long strict gluten-free diet (GFD), which normally leads to a complete remission of the clinical symptoms and recovery of the mucosal lesion $(1,2)$.

The most accepted model for explaining CD immunopathogenesis is the twosignal model (11) characterized by a first innate immune response followed by a secondary antigen-specific adaptive response. On a first step, some gliadin toxic peptides trigger an innate immune response $(12,13)$ in a HLA-DQ2/8 independent manner mainly characterized by the production of IL-15 by epithelial cells $(14,15)$, which has maximum effects on CD patients as they have an increased duodenal expression of IL-15 receptor coupled with a lower immune response threshold against such cytokine (16). That results in the disruption of the epithelial barrier, both by directly increasing the permeability throughout the tight-junctions $(17,18)$ and by inducing enterocyte apoptosis after intraepithelial lymphocyte reprogramming into NK-like cells $(19,20)$. As a consequence, gliadin immuno-adaptive peptides can now reach the lamina propria where they are deaminated by the enzyme tTG. Such deamination confers a negative load to gliadin peptides which can now fit in the HLA-DQ2/8 presenting molecule expressed on lamina propria dendritic cells (DC) (21-23). Activated DC subsequently present gluten peptides to nä̈ve T-cells which differentiate towards pro-inflammatory gluten specific T-cells $(24,25)$ and drive a pro-inflammatory response which promotes a histological lesion characterized by a massive intraepithelial infiltration of lymphocytes, crypt hyperplasia and villous atrophy $(5,12,13)$ which at the end will turn into the symptomatology of the disease $(1,2)$. As for the pathogenesis of non-CD gluten intolerance patients, who are negative for both genetic and serological markers although have gluten-induced duodenal pathological changes, one explanation is that the two-signal model is truncated 
and such patients develop the first innate immune response which, however, is not coupled with the secondary and antigen-specific adaptive immune response as they lack the machinery for gluten antigen presentation (26).

CD diagnosis is currently based on genetical (HLA-DQ2+ and/or HLA-DQ8+) and serological markers (IgA anti-endomysial and/or IgA-tTG) coupled with duodenal histological alterations as assessed by duodenal endoscopy. Although the latter can be omitted in some cases like in first degree relatives of CD patients with both positive serology/genetics and clinically compatible symptoms, duodenal endoscopy is still the gold standard for CD diagnosis. Nevertheless, not all the patients agree with the need of a duodenal endoscopy especially those with silent or latent forms with no clinical symptomatology and/or those with non-CD gluten intolerance. The need of less invasive approaches for CD diagnosis is therefore a real need. Indeed, less invasive approaches would also allow an easier assessment of mucosal recovery after GFD allowing a better management of the disease.

In the current issue of Revista Española de Enfermedades Digestivas (The Spanish Journal of Gastroenterology), Bardellini et al. (27) present an interesting study addressing the question as to whether the oral mucosa could resemble the histopathological characteristics of the duodenal one in CD patients. In their cross-sectional study, they authors recruited a total of $18 \mathrm{CD}$ patients at the moment of diagnosis (and therefore untreated), 19 CD patients following GFD for a variable amount to time and 15 healthy volunteers. Buccal biopsy specimens were obtained in all cases from normal looking mucosa for immunohistochemical characterization of T-cell subsets (CD3, CD4, CD8 and $T \gamma \delta$ ). Duodenal samples were obtained from CD patients too. All untreated CD patients had a Marsh severity score over 3 (5) confirming CD diagnosis. The novelty of the work of Bardellini et al. (27) relies in the fact that they also described a dense inflammatory infiltrate rich in lymphoid cells with a considerable increase in $T \gamma \delta$ cells in the buccal mucosa from such untreated CD patients. GFD-treated patients displayed duodenal severity scores ranging from Marsh 0-2 (5), which was also mirrored by a slight increase of the buccal inflammatory infiltrate if compared with healthy controls but certainly lower than that reported in the untreated CD group. The findings from Bardellini et al. (27) in the buccal mucosa reflect therefore what has been shown to happen in the intestinal mucosa, where although GFD abolishes symptoms and normalizes serological markers, does not fully normalize in all CD patients in whom clinical remission is achieved (28). Such findings have therefore great relevance for CD diagnosis and/or mucosal recovery assessment following GFD as the buccal mucosa provides a more accessible tissue to assess the duodenal status.

The findings from Bardellini et al. (27) and other similar observations (29) are however opposed to other recent studies $(30,31)$ which found no differences regarding oral mucosa lymphocyte infiltrate in $\mathrm{CD}$ patients when compared with healthy controls. Therefore, more studies similar to the one by Bardellini et al. (27) should be performed including larger multi-center cohorts and a blinded comparison of the duodenal and buccal immunohistochemistry analysis to confirm their findings. Other studies should also address the mechanisms controlling the lymphocyte infiltrate at the buccal mucosa. Is the buccal mucosa responding to the ingested gluten or it is mirroring the duodenum? If the latter, what is the mechanism controlling that? Are the buccal lymphocyte infiltrates gluten specific? Are there other cell infiltrates like DC? Some of such intriguing questions could be answered via DC and/or T-cell subset characterization of the buccal biopsies (flow cytometry, immunohistochemistry...) and/or immune mediators (ELISA, Western-blot...) production of the buccal explants both in freshly obtained biopsies and after in vitro 
gluten/gliadin challenge from CD (treated/untreated) patients and non-CD controls. Also, it cannot be discarded that the buccal infiltrates may be a consequence of altered leukocyte trafficking in $\mathrm{CD}$ patients (32), which could be reflected in altered homing profile of circulating leukocyte as recently reported in CD patients even on the GFD (33). Finally, the findings from Bardellini et al. (27) may also have implication to study the pathogenesis and/or diagnosis of non-CD gluten intolerance patients as it would also be very interesting to study if such group of patients also display such "Marsh-like" lesion at the buccal mucosa which would throw some light into the, still evasive, mechanisms controlling non-CD gluten intolerance.

David Bernardo

Imperial College London. Antigen Presentation Research Group. Northwick Park \& St Mark's Hospital. Watford Road, Harrow. United Kingdom

\section{REFERENCES}

1. Sollid LM. Coeliac disease: Dissecting a complex inflammatory disorder. Nat Rev Immunol 2002;2:647-55.

2. Jabri B, Sollid LM. Mechanisms of disease: Immunopathogenesis of celiac disease. Nat Clin Pract Gastroenterol Hepatol 2006;3:516-25.

3. Comino I, Real A, de Lorenzo L, Cornell H, López-Casado MA, Barro F, et al. Diversity in oat potential immunogenicity: Basis for the selection of oat varieties with no toxicity in coeliac disease. Gut 2011;60:915-22.

4. Real A, Comino I, de Lorenzo L, Merchán F, Gil-Humanes J, Giménez MJ, et al. Molecular and immunological characterization of gluten proteins isolated from oat cultivars that differ in toxicity for celiac disease. PLoS One 2012;7:e48365.

5. Marsh MN. Gluten, major histocompatibility complex, and the small intestine. A molecular and immunobiologic approach to the spectrum. Gastroenterology 1992;102:330-54.

6. Riestra S, Fernández E, Rodrigo L, Garcia S, Ocio G. Prevalence of coeliac disease in the general population of northern Spain. Strategies of serologic screening. Scand J Gastroenterol 2000;35:398-402.

7. West J, Logan RF, Hill PG, Lloyd A, Lewis S, Hubbard R, et al. Seroprevalence, correlates, and characteristics of undetected coeliac disease in England. Gut 2003;52:960-5.

8. Catassi C, Rätsch IM, Fabiani E, Rossini M, Bordicchia F, Candela F, et al. Coeliac disease in the year 2000: Exploring the iceberg. Lancet 1994;343:200-3.

9. Verdu EF, Armstrong D, Murray JA. Between celiac disease and irritable bowel syndrome: The no man's land of gluten sensitivity. Am J Gastroenterol 2009;104:1587-94.

10. Biesiekierski JR, Newnham ED, Irving PM, Barrett JS, Haines M, Doecke JD, et al. Gluten causes gastrointestinal symptoms in subjects without celiac disease: A double-blindrandomized placebo-controlled trial. Am J Gastroenterol 2011;106:508-14.

11. Brandtzaeg P. The changing immunological paradigm in coeliac disease. Immunol Lett 2006;105:127-39.

12. Londei M, Ciacci C, Ricciardelli I, Vacca L, Quaratino S, Maiuri L. Gliadin as a stimulator of innate responses in celiac disease. Mol Immunol 2005;42:913-8.

13. Maiuri L, Ciacci C, Ricciardelli I, Vacca L, Raia V, Auricchio S, et al. Association between innate response to gliadin and activation of pathogenic T cells in coeliac disease. Lancet 2003;362:30-7.

14. Di Sabatino A, Ciccocioppo R, Cupelli F, Cinque B, Millimaggi D, Clarkson MM, et al. Epithelium derived interleukin 15 regulates intraepithelial lymphocyte Th1 cytokine production, cytotoxicity, and survival in coeliac disease. Gut 2006;55:469-77.

15. Bernardo D, Garrote JA, Fernández-Salazar L, Riestra S, Arranz E. Is gliadin really safe for non-coeliac individuals? Production of interleukin 15 in biopsy culture from non-coeliac individuals challenged with gliadin peptides. Gut 2007;56:889-90.

16. Bernardo D, Garrote JA, Allegretti Y, León A, Gómez E, Bermejo-Martin JF, et al. Higher constitutive IL15R alpha expression and lower IL-15 response threshold in coeliac disease patients. Clin Exp Immunol 2008;154:64-73.

17. Matysiak-Budnik T, Candalh C, Dugave C, Namane A, Cellier C, Cerf-Bensussan N, et al. Alterations of the intestinal transport and processing of gliadin peptides in celiac disease. Gastroenterology 2003;125:696-707.

18. Clemente MG, De Virgiliis S, Kang JS, Macatagney R, Musu MP, Di Pierro MR, et al. Early effects of gliadin on enterocyte intracellular signalling involved in intestinal barrier function. Gut 2003;52:218-23.

19. Meresse B, Chen Z, Ciszewski C, Tretiakova M, Bhagat G, Krausz TN, et al. Coordinated induction by IL15 of a TCR-independent NKG2D signaling pathway converts CTL into lymphokine-activated killer cells in celiac disease. Immunity 2004;21:357-66.

20. Hüe S, Mention JJ, Monteiro RC, Zhang S, Cellier C, Schmitz J, et al. A direct role for NKG2D/MICA interaction in villous atrophy during celiac disease. Immunity 2004;21:367-77. 
21. Ráki M, Tollefsen S, Molberg Ø, Lundin KE, Sollid LM, Jahnsen FL. A unique dendritic cell subset accumulates in the celiac lesion and efficiently activates gluten-reactive T cells. Gastroenterology 2006;131:428-38.

22. Tollefsen S, Arentz-Hansen H, Fleckenstein B, Molberg O, Ráki M, Kwok WW, et al. HLA-DQ2 and -DQ8 signatures of gluten T cell epitopes in celiac disease. J Clin Invest 2006;116:2226-36.

23. Beitnes AC, Ráki M, Brottveit M, Lundin KE, Jahnsen FL, Sollid LM. Rapid accumulation of CD14+CD11c+ dendritic cells in gut mucosa of celiac disease after in vivo gluten challenge. PLoS One 2012;7(3):e33556.

24. Nilsen EM, Lundin KE, Krajci P, Scott H, Sollid LM, Brandtzaeg P. Gluten specific, HLA-DQ restricted $\mathrm{T}$ cells from coeliac mucosa produce cytokines with $\mathrm{Th} 1$ or Th0 profile dominated by interferon gamma. Gut 1995;37:766-76.

25. Bernardo D. Human intestinal dendritic cells as controllers of mucosal immunity. Rev Esp Enferm Dig 2013;105:279-290.

26. Bernardo D, Garrote JA, Arranz E. Are non-celiac disease gluten-intolerant patients innate immunity responders to gluten? Am J Gastroenterol 2011;106:2201.

27. Bardellini E, Amadori F, Ravelli A, Salemme M, Lonardi S, Villanacci V, et al. Histopathological findings in the oral mucosa of celiac patients. Rev Esp Enferm Dig 2014;106:86-91.

28. Bardella MT, Velio P, Cesana BM, Prampolini L, Casella G, Di Bella C, et al. Coeliac disease: A histological follow-up study. Histopathology 2007;50:465-71.

29. Lähteenoja H, Toivanen A, Viander M, Räihä I, Rantala I, Syrjänen S, et al. Increase in T-cell subsets of oral mucosa: A late immune response in patients with treated coeliac disease? Scand J Immunol 2000;52:602-8.

30. Compilato D, Campisi G, Pastore L, Carroccio A. The production of the oral mucosa of antiendomysial and anti-tissue-transglutaminase antibodies in patients with celiac disease: A review. Scientific World Journal 2010;10:2385-94.

31. Campisi G, Compilato D, Iacono G, Maresi E, Di Liberto C, Di Marco V, et al. Histomorphology of healthy oral mucosa in untreated celiac patients: Unexpected association with spongiosis. J Oral Pathol Med 2009;38:34-41.

32. Hart AL, Ng SC, Mann E, Al-Hassi HO, Bernardo D, Knight SC. Homing of immune cells: Role in homeostasis and intestinal inflammation. Inflamm Bowel Dis 2010;16:1969-77.

33. Comino I, Šuligoj T, Al-Hassi HO, Lee GH, Sousa C, Landy J, et al. Constitutive gut-homing capacity on circulating myeloid dendritic cells in coeliac disease. Rev Esp Enferm Dig 2014;106:64-5. 